\title{
O espaço na geografia e o espaço da arquitetura: reflexões epistemológicas
}

\author{
Space in geography and the space \\ of architecture: epistemological reflections
}

Lucia Leitão Norma Lacerda

\begin{abstract}
Resumo
A geografia e a arquitetura constituem duas áreas do conhecimento, cujos respectivos corpos disciplinares se debruçam, aparentemente, sobre o mesmo objeto - o espaço. Esse é o ponto de partida destas notas teóricas, cujo objetivo é chamar a atenção para certas distinções epistemológicas nas aludidas áreas. Para tanto, na primeira parte, ressalta-se que, apenas a partir da década de 1970, o conceito de espaço se tornou alvo de análise crítica explícita por parte dos geógrafos, e anunciam-se possíveis diferenciações desse conceito, em confronto com a formulação teórica do espaço arquitetônico. Na segunda parte, indicam-se as especificidades teórico-metodológicas que definem o espaço arquitetural. Espera-se que as reflexões ora apresentadas contribuam para a minimização de possíveis confusões epistemológicas.
\end{abstract}

Palavras-chave: espaço; teoria; geografia; arquitetura.

\begin{abstract}
Geography and architecture are two areas of knowledge whose respective subject corpora apparently focus on the same object - space. This is the starting point of these theoretical notes, the objective of which is to draw attention to certain epistemological distinctions between the abovementioned areas. Therefore, in the first part, it is noted that it was only in the 1970s that the concept of space became a key concept of geography. Moreover, possible differentiations of this concept are announced in comparison with the theoretical formulation of architectonic space. In the second part, the theoretical and methodological specificities that define architectural space are indicated. It is hoped that the reflections presented in this article will contribute to minimize possible instances of epistemological confusion.
\end{abstract}

Keywords: space; theory; geography; architecture. 


\section{Introdução}

Estas notas resultaram da percepção da ocorrência de certa "confusão" conceitual, relativamente ao emprego do termo espaço, quando se trata de refletir à luz da geografia ou da arquitetura. Essa "confusão" vem-se manifestando, com frequência, na produção acadêmica recente, de modo especial em dissertações e teses apresentadas em programas de pós- graduação, ao se debruçarem sobre esses dois campos disciplinares.

Como disciplinas autônomas, pressupõe-se que cada uma delas detenha o necessário domínio de conceitos, categorias e métodos de abordagem específicos, de modo a permitir-Ihes, com a necessária precisão epistemológica, a constituição do próprio objeto de investigação. Afinal, como bem anota Santana (2008, p. 1), "mesmo que várias ciências tenham o mesmo objeto material, cada uma delas tem seu exclusivo objeto formal e, portanto, a sua marca individualizadora".

A empreitada intelectual de delimitação de marcas distintivas da geografia, em relação à arquitetura - e vice-versa -, é seguramente desafiadora e excede os limites e objetivos do presente texto. Com efeito, ela implicaria demarcar precisamente o arcabouço teórico-metodológico de cada uma dessas disciplinas, tarefa ainda inconclusa, mesmo para importantes teóricos desses dois campos do conhecimento. Nesse sentido, Milton Santos, sabidamente um dos maiores expoentes da geografia brasileira, registra, com razão, que essa disciplina se ressente de uma epistemologia claramente expressa e, à conta disso, "a própria geografia tem dificuldade para participar em um debate filosófico e interdisciplinar" (Santos, 2006, p. 28). ${ }^{1}$

Talvez essa dificuldade explique parte da confusão teórica, aqui mencionada, notadamente quando a geografia "se encontra" com campos disciplinares de interfaces comuns, a exemplo da arquitetura. Por sua vez, do ponto de vista da arquitetura, no que diz respeito a lacunas ou a inconclusões teóricas - em que pesem a contribuição de tratadistas célebres e dois milênios de prática disciplinar ${ }^{2}$-, é ainda recente a percepção de que o espaço é o protagonista da arquitetura (Zevi, 1977).

É, pois, nesse contexto de imprecisões teóricas que se delineiam aqui, embora de modo sucinto, especificidades teórico-metodológicas dessas duas áreas do conhecimento, cujos respectivos corpos disciplinares se debruçam, aparentemente, sobre o mesmo e único objeto - o espaço. Espera-se, com isso, contribuir para a minimização de possíveis confusões epistemológicas.

0 trabalho está organizado em duas partes. Na primeira, recapitulam-se a constituição e a evolução da geografia, enquanto campo disciplinar. 0 intuito é mostrar que, só a partir da década de 1970 - sobretudo com a emergência da geografia crítica -, o espaço, até então objeto meramente implícito dessa disciplina, passou a ser analisado, de forma expressa e direta, na sua natureza de conceito central da atividade dos geógrafos. Na segunda parte do texto, volta-se a atenção para as especificidades teóricas e metodológicas do espaço da arquitetura. 


\section{0 espaço da geografia: construção histórica e epistemológica}

A origem etimológica do vocábulo geografia - contrariamente à gênese da palavra arquitetura, como se verá adiante - não ajuda a aclarar o conceito de espaço, no âmbito dessa disciplina. Geografia é termo derivado de dois radicais gregos: geo (terra) e graphein (descrever). Sob esse aspecto, ela se restringiria a fazer a descrição da superfície da Terra. Como tal, dificilmente poderia ser alçada ao status de atividade científica. Todavia, a evolução das correntes do pensamento geográfico, na era contemporânea, oferece um caminho para entender como o espaço passou a constituir um conceito-chave nessa área do saber.

Corrêa (2001) identifica, nessa evolução, três períodos. 0 primeiro tem início nos anos de 1870 - quando a geografia foi institucionalizada, enquanto disciplina, nas universidades europeias - e se estende até a década de 1950. Os trabalhos de Alexandre von Humboldt e Karl Ritter foram decisivos nesse processo de formalização (Andrade, 2006). Tal período corresponde ao que se convencionou denominar geografia tradicional, cujos conceitos centrais eram o de paisagem e o de região.

0 trabalho de Humboldt tinha por fundamento a descrição e a representação das estruturas naturais. A vegetação era valorizada, como fonte de interpretação e entendimento da paisagem. Esta, porém, não se limitava ao universo natural. 0 estudo da Terra deveria incorporar o elemento humano. Foi assim que, segundo Vitte (2007), originou-se o conceito de paisagem geográfica. Mais adiante se retomará o conceito de paisagem, uma vez que, além de incisivamente retomado pela geografia, reporta-se à materialidade do espaço, aspecto também considerado pela arquitetura, muito embora de modo distinto.

Para Corrêa (2001, p. 17), "a abordagem espacial, associada à localização das atividades humanas e aos fluxos, era muito secundária entre os geógrafos $(. . .)^{\prime \prime}$. Significa isso que o espaço não constituía conceito-chave para a geografia, fazendo-se presente apenas de forma implícita. Soja (1993), por sua vez, ao refletir sobre as origens das geografias pós-modernas, considera que era sempre o tempo e a história que forneciam os "continentes variáveis" primordiais nessas geografias. Segundo suas próprias palavras:

Isso parece igualmente claro, quer a orientação crítica seja descrita como sociológica, quer como política ou antropológica - ou, a rigor, fenomenológica, existencial, hermenêutica ou materialista histórica. As ênfases específicas podem diferir, mas a perspectiva geral é compartilhada. Uma geografia já pronta prepara o cenário, enquanto a construção intencional da história dita a ação e define 0 roteiro. (p. 22)

Era, portanto, uma geografia reduzida à descrição da disposição dos elementos dos cenários, onde os atores sociais se empenhavam em fazer a história. A geografia não participava, então, do competitivo embate da construção teórica.

Para esse autor, o historicismo - definido como "uma contextualização histórica hiperdesenvolvida da vida social e da teoria social" - obscurece a imaginação espacial. Mais ainda, representa uma subordinação implícita 
do espaço ao tempo, uma subordinação que tolda as interpretações geográficas da mutabilidade do mundo e se intromete, segundo o ele, em "todos os níveis do discurso teórico, desde os mais abstratos conceitos ontológicos do ser até as explicações mais detalhadas dos acontecimentos empíricos" (ibid., p. 23). Em suas linhas essenciais, Soja questiona a hegemonia do historicismo no pensamento crítico e não a importância da história, naturalmente.

0 segundo período abrange as décadas de 1950 e 1960 . Corresponde ao surgimento da geografia teorético-quantitativa. É quando ela passa a ser considerada uma ciência social e a ser vista como uma ciência espacial. ${ }^{3}$ "0 espaço aparece, pela primeira vez na história do pensamento geográfico, como o conceito-chave da disciplina" (Corrêa, 2001, p. 20). Da geografia tradicional - praticamente ateórica despontava uma nova versão, crescentemente técnica e matematizada, da descrição geográfica. Fundamentada primordialmente "na física social, nas ecologias estatísticas e em apelos acanhados à onipresente fricção de distância" (Soja, 1993, p. 67), as análises geográficas de então consideravam a distância - e não o espaço - como a variável mais importante. Apesar da introdução da variável localização, a realidade continuava a ser explicada por fatores físicos. Tal sistema de pensamento se tornou conhecido como determinismo geográfico, há muito abandonado.

Como fruto desse pensamento, surgiram a noção de centro-periferia - nas escalas intraurbana, nacional e internacional - e a de espaço relativo, apontada por Harvey (1969, apud Corrêa, 2001). ${ }^{4}$ Não sem razão, foram desenvolvidos, nesse período, inúmeros modelos de organização espacial, que privilegiavam o presente e, por extensão, relegavam a segundo plano as transformações, as contradições e os conflitos. A geografia restringia-se, assim, ao campo do mensurável, "morto, não dialético, imóvel", nas palavras do filósofo francês Michel Foucault (1976, p. 159). Conformava, desse modo, um conhecimento aplicado a serviço do Estado, ou seja, uma forma coadjuvante da ciência da administração e do planejamento estatais e das empresas privadas. Dessa forma, isolou-se da história, das ciências sociais e do "marxismo ocidental". 5

Por "marxismo ocidental", entenda-se uma corrente de pensamento que se afastou das ortodoxias centrais do marxismo-leninista. ${ }^{6}$ Segundo Soja (1993), muito embora esse marxismo abordasse o espaço como um receptáculo e um espelho da sociedade, foi a partir dessa corrente que o espaço e a crítica ao historicismo acabaram por firmar-se, ao inaugurarem o terceiro período da geografia o da geografia crítica, de 1970 em diante.

Fundamentada no materialismo histórico e na dialética, essa nova corrente do pensamento geográfico rompeu com a geografia tradicional e com a teorético-quantitativa. 0 espaço (re)apareceu como conceito-chave.

A partir do pensamento de Henri Lefebvre, passou o espaço a ser abordado como o lócus da reprodução das relações sociais e, portanto, da sociedade. Filósofo e sociólogo por formação, a concepção de "produção do espaço" de Lefebvre derivou do "jogo de forças", econômica, política e socialmente definido. Consoante o autor:

Quando o espaço social deixa de se confundir com o espaço mental (definido pelos filósofos e pelos matemáticos), com o espaço físico (definido pelo 
prático-sensível e pela percepção da "natureza"), ele revela sua especificidade. Será preciso mostrar que esse espaço social não consiste numa coleção de coisas, numa soma de fatos (sensíveis), nem tão somente num vazio preenchido, como uma embalagem, de matérias diversas, que ele não se reduz a uma forma imposta aos fenômenos, às coisas, à materialidade física. 0 caráter social do espaço, afirmado aqui como prévia (hipótese), será confirmado durante a exposição [que o autor faz em seguida]. (1986, p. 36)

Assim, o espaço de que trata Lefebvre é socialmente definido e, portanto, abstrato, em termos materiais, embora se assente no território e se expresse na materialidade do ambiente construído, com desdobramentos metodológicos específicos. Dito de outra forma, o espaço lefebvriano é metodologicamente analítico e fisicamente abstrato, conquanto, repita-se, assentado no território - uma especificidade epistemológica do espaço social, em tudo distinta do espaço da arquitetura, como se analisará adiante.

Milton Santos, cuja obra foi fortemente inspirada no autor acima aludido, defende o conceito de formação socioespacial ou, simplesmente, formação espacial, calcado na ideia de não ser plausível conceber uma determinada formação socioeconômica, sem se recorrer à noção de espaço. Esse eminente estudioso considera que, por um lado, qualquer sociedade se revela, concretamente, por meio do espaço produzido. Mas também que, por outro, o espaço é inteligível por meio da sociedade, porquanto não se trata de realidades sociais distintas. Nessa perspectiva, a abordagem analítica do espaço exige, ainda segundo Santos, lançar-se mão de quatro categorias: função, forma, estrutura e processo.

A função diz respeito à atividade desempenhada pelo objeto e está tradicionalmente associada à forma. Ambas as categorias - forma e função -, por sua vez, não podem, nem devem ser dissociadas da estrutura social e econômica, sob o risco de impossibilitar-se a apreensão da natureza do espaço. Afinal, essa estrutura é a matriz em que as formas e as funções se justificam. Acontece que essa estrutura se encontra em constante mutação, ou seja, em movimento contínuo, conformando-se, por isso mesmo, como processo.

Para Santos, a forma é um elemento analítico na apreensão socioespacial de um dado ambiente construído. Ela não tem, portanto, autonomia em si mesma, com relação à produção espacial desse ambiente, 0 que a distingue, conceitualmente, da forma arquitetônica, conforme se verá na segunda parte do presente texto.

Comentando a respeito da categoria forma, e citando Santos, Corrêa anota que ela

[...] não deve ser considerada em si mesma, sob o risco de atribuir a ela uma autonomia de que não é possuidora. Se assim fizermos, estaremos deslocando, para a esfera da geometria, a linguagem da forma, caindo em um especialismo estéril. Por outro lado, ao considerarmos isoladamente a forma espacial, apreenderíamos apenas a aparência, abandonando a essência e as relações entre esta e a aparência. (2001, p. 28)

Nesse ponto, importa não confundir a autonomia da forma, enquanto expressão volumétrica que, na verdade, seria de um campo disciplinar específico - a arquitetura -, com 
os atributos indispensáveis à definição dessa forma, necessariamente geométricos. Afinal, o espaço edificado se define por linhas (retas e curvas), comprimentos, larguras, alturas e profundidades, inescapáveis à construção do ambiente concreto. Em outras palavras, longe de constituir um especialismo estéril, a composição geométrica, na constituição da forma, desta feita arquitetônica, é condição indispensável para que sejam materializados os objetos socioespaciais a que ela se referem (ver Figuras $5,6,7,9$ e 10).

$\mathrm{Na}$ verdade, o que Santos deixa à mostra, no texto citado, é a forma do espaço social, (geográfica, portanto), isto é, forma territorialmente localizada, que explicita valores, demandas e reclamos socialmente produzidos. Essa forma, porém, materializa-se por meio da arquitetura, que cada sociedade edifica. Como se vê, embora a expressão vocabular seja a mesma - forma -, trata-se de duas expressões epistemologicamente distintas, ou seja, enquanto, na perspectiva geográfica, "a forma não deve ser considerada em si mesma, sob o risco de atribuir-se a ela uma autonomia de que não é possuidora", do ponto de vista arquitetônico, a forma é autônoma em si mesma - no tanto em que delimita e, com isso, cria o espaço arquitetônico.

Assim, é possível que uma leitura apressada de Lefebvre e, posteriormente, de Santos tenha fomentado a "confusão" entre esses dois campos disciplinares - arquitetura e geografia. Por isso, quando se pensa a noção de espaço, importa precisar - no sentido que os franceses atribuem a esse termo -, conceitualmente, de que espaço se está tratando, ocorrendo o mesmo com forma e função, conceitos e categorias que, embora comuns a esses dois campos do conhecimento, só podem ser apreendidos, de modo adequado, sob um enquadramento epistemológico distinto, conforme se pretende evidenciar com estas notas.

Retomando-se a sequência evolutiva do pensamento geográfico, registre-se que a década de 1970 também assistiu à emergência da geografia humanística e cultural, calcada nas filosofias do significado, especialmente na fenomenologia e no existencialismo. Ela se assenta na subjetividade, nos sentimentos, no simbolismo e privilegia o singular, em detrimento do universal. Para ela, a compreensão constitui a base de inteligibilidade do mundo. No âmbito dessa geografia, a ideia de paisagem passa a ser revalorizada, e as noções de território e de lugar transformam-se em elementos fundamentais.

0 conceito de paisagem refere-se à materialidade, ao conjunto das formas que, em dado momento, revelam as heranças decorrentes das sucessivas relações localizadas entre 0 homem e a natureza (Santos, 2006). ${ }^{7}$ Sobre 0 conceito de paisagem cultural, geógrafos, como Ducan (2000) e Corrêa e Rosendalh (2000), afirmam ter sido essencial, no seu processo de construção, a interdisciplinaridade. Aliás, é consenso, entre os geógrafos, que a abordagem da geografia cultural se encontra cada vez mais envolvida com questões políticas, econômicas e sociais, demandando uma abordagem integradora (Haesbaert apud Barbosa, 2014). Não fazem, porém, qualquer alusão à arquitetura, como se essa disciplina nada tivesse a oferecer à análise do espaço geográfico. Eles desconhecem, ou desconsideram, aparentemente, pelo menos dois mil anos de sistematização teórica e de intervenção projetada da arquitetura, na conformação do ambiente construído. 
Esse conceito de paisagem cultural corresponde, em suas linhas essenciais, "à forma, aos aspectos visuais de um território, mas também ao conjunto de narrativas e qualidades discursivas, que falam e constroem essa porção territorial" (Barbosa, 2014), sendo edificada a partir de relações de poder, sociais, econômicas, políticas e culturais, dentre outras. Dunlop (2010, p.18) afirma que a geografia mantém uma relação paradoxal com a noção de paisagem: "Ela [a geografia] a define como uma percepção subjetiva e instantânea, bem diferente de uma porção do espaço terrestre objetivo, e também como um dos seus objetos de estudo enquanto ciência".

Segundo esse autor, os geógrafos se interessam pelas paisagens de duas maneiras distintas: 1) por meio de fotografias, vídeos, ilustrações, mapas, cartogramas, etc., por eles produzidos, quando tais elementos constituem parte dos seus discursos científicos sobre 0 seu objeto de estudo: o espaço geográfico; 2) e mediante a análise de paisagens trabalhadas por outros profissionais (artistas, publicitários, urbanistas, etc.), quando visam compreender como as sociedades veem, julgam e imaginam seu entorno espacial.

A reflexão de Dunlop é essencial para a compreensão das motivações dos atores que constroem os territórios. Nessa perspectiva, fica claro que os geógrafos se debruçam sobre o seu objeto de estudo - o espaço - de modo analítico (interpretativo e crítico), mas não projetado. Por seu turno, o espaço projetado constitui o objeto próprio do fazer arquitetônico, como se verá a seguir.

\section{0 espaço da arquitetura e suas especificidades epistemológicas}

Evaldo Coutinho, em texto hoje clássico (1977), vê a arquitetura como sendo a composição de um vazio. ${ }^{8} \mathrm{Com}$ isso, oferece um bom ponto de partida para as notas que se esboçam aqui a respeito da natureza do espaço da arquitetura.

Diferentemente da concepção de espaço em outros campos disciplinares, o espaço arquitetônico se define por um vazio que 0 constitui em consequência de uma ação humana compositiva. Em outras palavras, o espaço da arquitetura é necessariamente projetual. Não se confunde, portanto, teoricamente, com o espaço preexistente que dá suporte físico-ambiental a essa ação projetual, tampouco se confunde com o espaço social - essencialmente analítico, como se anotou antes -, promotor dessa ação.

A etimologia do vocábulo arquiteto architektôn - oferece um caminho a seguir quando se busca mostrar a especificidade projetual do fazer arquitetônico, objetivo destas notas, uma vez que, ao se ter em mente o sentido etimológico desse vocábulo, têm-se também as primeiras indicações do que é especifico da arquitetura como campo disciplinar.

Ao refletir sobre o que é arquitetura, Salignon anota que "princípio, em grego, se diz arkhê, prefixo presente na palavra (arqui)tetura". Assim, na palavra arquitetura, continua 0 autor, "[...] devemos compreender arkhê como sendo a um só tempo princípio originário, 
[ideia] e a [ação] que faz surgir, [pela vez primeira] algo que não existia [...]" (2001a, p. 161). ${ }^{9}$ Tektôn, por sua vez, indica, em grego, o construtor, o "mestre carpinteiro", aquele que, no exercício do seu ofício, compõe e, como consequência dessa ação compositiva, ergue a edificação, donde se tem, em português, a palavra tectônica, a arte de construir edifícios, como ensina o Houaiss.

Arquitetar é, pois, nesse sentido, uma ação humana criadora, " [...] que faz aparecer o que não existia em nenhuma parte", escreve Hannah Arendt, conforme registra ainda Salignon (2001b, p. 83), como resultado de uma atividade projetiva a um só tempo pessoal e coletiva. Uma ação que faz surgir, no contexto destas notas, o ambiente construído, inexistente até o momento em que se deu justamente essa ação projetual originária.

Assim, perseguindo-se o sentido etimológico do vocábulo architektôn, tem-se anunciada uma primeira indicação da natureza do espaço arquitetural. 0 espaço da arquitetura se constitui em consequência de uma proposição humana (arkhê) compositiva (tektôn) que o faz surgir, proposição esta teórica e metodologicamente definida, conforme se verá adiante.

0 espaço arquitetural não se confunde, portanto, com o espaço natural preexistente à ação humana criadora, propositiva, ainda que o espaço preexistente se modifique pela presença humana. Em outras palavras, embora fundamental à composição do vazio, o espaço natural não se confunde, teoricamente, com o espaço da arquitetura, uma vez que o espaço natural é um espaço modificado, mas não originado, menos ainda composto, por uma ação humana propositiva.
Nessa perspectiva, o ambiente natural que dá suporte ao fazer arquitetônico é um espaço "[...] que se dá como espaço para o homem" (Salingon, 1997, p. 92). Um espaço existente antes de qualquer gesto originário arkhê - humano, e não um espaço que surge em decorrência desse gesto. Nesse sentido, continua o autor, a criação do espaço da arquitetura "[...] é negação do espaço [natural] e afirmação [proposição, criação] de lugar" (1997, p. 93) projetualmente humano.

Edificar, ou arquitetar, ${ }^{10}$ é, portanto, nesse sentido, a expressão de uma habilidade humana, análoga à da linguagem, manifesta num ato fundador próprio da condição humana, como bem assinala Choay (2006). Uma ação que realiza "[...] o imperativo de passar entre o que há [o espaço que se dá como espaço para o homem] e o que não há ainda [o espaço composto, edificado pelo homem]" (Salignon, 1997, p. 96).

Talvez se tenha aqui - nesse imperativo - uma resposta plausível a uma questão importante para a Teoria da Arquitetura, em especial para aqueles que se dedicam a investigar as razões da construção d'A casa de Adão no paraíso (Rykwert, 1997), isto é, as motivações primeiras presentes na edificação do espaço humano.

Olivier Marc formula essa questão nos seguintes termos: "Por que o homem primitivo foi levado a construir sua casa, rejeitando o abrigo que a natureza lhe oferecia sob a forma de uma gruta ou caverna?" (1972, p. 19). A resposta parece surgir desse imperativo humano de afirmar um lugar como criação. Afinal, a caverna não é algo originário de nenhuma ação humana propositiva. Não é, portanto, 
Figura 1- A caverna de Lascaux (Mumford, 1982) o espaço que se dá como espaço para o homem

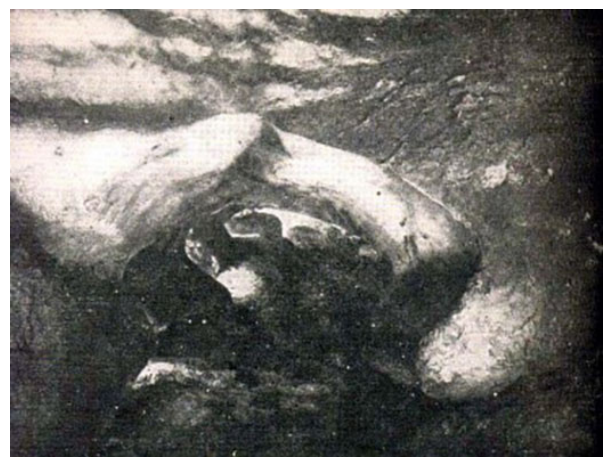

Figuras 2 e 3 - Construções megalíticas - o espaço criado pela ação humana
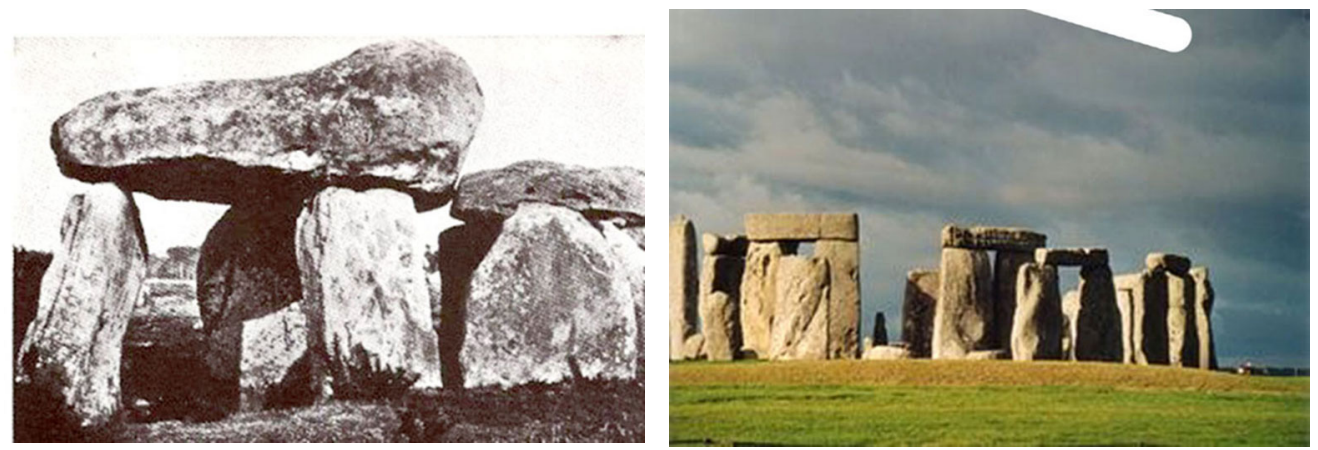

uma composição humana nem se destina ao uso humano. Menos ainda realiza o imperativo humano de passar do estado de natureza ao estado de cultura (Lévi-Strauss, 2009, e Argan, 1966).

Nesse ponto, tem-se, precisamente, a primeira distinção epistemológica do espaço da arquitetura. 0 espaço arquitetural é um espaço criado, originado - e não apenas modificado ou transformado - pela e para a ação humana, ante um ambiente natural que se dá como espaço para o homem, preexistente, portanto, a qualquer ação humana.
Importa, pois, chamar a atenção do leitor para o fato de que esse ato fundador originário - arkhê -, começo de todos os começos da história humana, embora manifesto no fazer arquitetônico em sua expressão tectônica, é irredutível ao objeto arquitetural em sua materialidade. É possível que resida, nesse ponto, parte da "confusão" que se vê em alguns autores quando eles se debruçam sobre a questão do espaço edificado. Ao não perceberem essa distinção teórica fundamental entre o evento criador do ambiente construído e os elementos arquitetônicos que lhe dão materialidade, 
alguns confundem o espaço da arquitetura, em sua especificidade teórica, com o objeto construído, materializado pela tectônica.

Em outras palavras, perdeu-se de vista, nesse modo de ver a criação do espaço edificado, que 0 ato que instaura o fazer arquitetônico como expressão da condição humana não é redutível à edificação, mister do tektôn, no exercício do seu ofício. Precisamente por isso, por ter consciência dessa irredutibilidade teórica, Salignon, uma vez ainda, adverte: "É a arquitetura que se impõe ao arquiteto, e não o contrário" (2001a, p. 158). Tanto quanto é a linguagem que se impõe ao "animal falante", e não o oposto.

Uma "confusão", nesse sentido, aparece na obra de Henri Lefebvre, Espace et politique. Nessa obra, Lefebvre critica:

[...] certos arquitetos [que] se veem ou se fazem ver como demiúrgicos [...], capazes de impor à sociedade sua concepção e sua definição de espaço. 0 demiúrgico platônico se encarnou na matéria, nos números e nas proporções, nos idealismos transcendentes. Esse espaço tem as seguintes características: vazio e puro lugar dos números e das proporções, ele é visual, desenhado [...]. (1972, p. 172)

Ao creditar ao tektôn a pretensão de uma ação demiúrgica, Lefebvre parece confundir o evento que origina o espaço humano - arkhê ação demiúrgica, sim, porque criadora, originária -, manifesto na arquitetura, mas irredutível a ela, com o ofício de um profissional em particular. Esse, sim, manifesto por meio de um vocabulário tridimensional, proposto, necessariamente, a partir de números e proporções.

Na Teoria da Arquitetura, a força desse ato criador originário, assim como sua irredutibilidade à tectônica, ainda que dela não prescinda, surge no célebre tratado De re aedificatoria, de Leon Battista Alberti, publicado originalmente em 1485.

Nesse texto clássico, Alberti atribui à construção do teto e do muro, ao ato de edificar, portanto, a instituição da vida em sociedade, a ponto de considerá-los - o teto e o muro - " [...] fatores certamente mais importantes do que a água e o fogo para reunir e manter unidas as comunidades humanas" (2011, p. 138, grifos meus). ${ }^{11}$ Afinal, diferentemente da água, fluida, e do fogo, volátil, o arquitetar propiciou as condições espaciais indispensáveis à permanência humana na face da Terra.

Choay (2006), muito apropriadamente, apreende desse texto seminal do erudito tratadista da arquitetura na Renascença a dimensão antropológica do ato de edificar - donde sua irredutibilidade ao objeto construído, isto é, foi o ato criador, essencialmente humano, insistimos, que, uma vez desencadeado com a edificação do teto e do muro, fez surgir o ambiente construído e, com ele, as condições edilícias essenciais à organização das sociedades humanas - reunir e manter unidos os homens, como escreveu Alberti -, donde se infere, precisamente, sua expressão antropológica.

Mumford (1982) ratifica essa ideia quando registra a importância do surgimento da aldeia neolítica como composição espacial para a organização das sociedades humanas então embrionárias. De fato, se a água e o fogo garantiam a vida do indivíduo e de pequenos grupos nômades no espaço que se dava para o homem de modo natural, a (arqui)tetura, fazendo surgir o que não existia ainda - o espaço edificado -, possibilitou a permanência dos 
grupos humanos num determinado ambiente, agora construído. Consequentemente, possibilitou a instituição da vida social, incipiente àquela altura.

Mas, para além dessa dimensão antropológica, cuja abordagem extrapola, evidentemente, os objetivos deste texto, qual é a natureza desse vazio originário, próprio de uma composição projetual, ante outros possíveis vazios igualmente compostos pela atividade humana?

A composição do espaço interior que acolhe o humano, definido por Bruno Zevi como sendo o fator distintivo da arquitetura diante das outras artes, indica uma segunda especificidade epistemológica do espaço da arquitetura. Em outras palavras, em termos edilícios, o que surge a partir da ação originária, arkhê, é, precisamente, o espaço "[...] interior [no qual] o homem entra e caminha", como escreve Zevi (1977, p. 17).

No entanto, se, a um olhar apressado do leigo, a ideia de espaço interior como resultante da composição do vazio próprio da arquitetura pode ser vista como óbvia, essa ideia ainda não é suficiente para a compreensão precisa do que é o espaço da arquitetura. Afinal, a escultura também produz espaços internos, que, no entanto, não se confundem com o espaço da arquitetura, uma vez que o espaço escultórico não se destina ao acolhimento humano em sua experiência cotidiana.

Desse modo, a inclusão do humano é condição inescapável para a demarcação conceitual do espaço da arquitetura. Por isso, Zevi, amparado em Kant e Hegel, assinala que o espaço interno que acolhe o humano se apresenta como fator distintivo da arquitetura, isto é, como aquilo que faz da arte de arquitetar algo diferente das demais artes visuais, apesar do que as assemelha. Anota Zevi:

A pintura realiza as quatro dimensões do espaço representando-se na superfície [...]. A escultura não só representa as quatro dimensões no plano e no volume, mas valoriza o movimento do observador que anda à sua volta [...]. Mas o fenômeno interno é substancialmente original: as cavidades, os vazios arquitetônicos, são indefiníveis no âmbito das quatro dimensões da pintura e da escultura. $(1979$, p. 56)

Assim, se a arquitetura compartilha, com a pintura, a habilidade de lidar com as dimensões geométricas e, com a escultura, a produção de um vazio presente num vaso ou taça qualquer, somente da arquitetura se espera a produção do espaço interno que inclui o humano, indefinível e inexistente no âmbito das dimensões presentes na pintura e na escultura.

É nessa perspectiva, ou sob esse modo de ver, que Zevi define a criação do espaço interior - composto, projetado, criado pela ação humana de arquitetar, ressalte-se uma vez ainda - como sendo o protagonista da arquitetura, como aquilo que a distingue em relação às outras artes, às artes visuais, notadamente. Assim, diz Zevi categoricamente: "Tudo o que não tem espaço interno não é arquitetura" (1977, p. 24).

Entender a arquitetura como a criação do espaço interior que inclui o humano implica rever a noção de interno (dentro) e externo (fora) tal como a apreende o senso comum. Do ponto de vista estritamente arquitetônico, há que se distinguir o espaço interno (o dentro), composto pelo arquitetar, onde os homens entram e vivem, especificidade epistemológica do 
fazer arquitetônico, do espaço externo (o fora), alheio à arquitetura, uma vez que esse espaço externo é o espaço que se dá como espaço para o homem, e não o espaço criado, composto, pelo homem.

Assim, se a composição do vazio constituinte do espaço interno, das cavidades, como escreve Zevi, distingue a arquitetura em relação às demais artes visuais, a destinação desse espaço - a inclusão do humano - distingue igualmente o espaço da arquitetura diante de outros possíveis espaços existentes na natureza e dos quais se ocupam outros campos disciplinares.

Em outras palavras, em termos epistemológicos, o espaço da arquitetura é necessariamente interno, interior. Ao discutir justamente esse ponto, o autor citado anota:

[...] a "distinção" entre o "espaço interno" próprio da arquitetura e o "espaço exterior" que define a urbanística é justificada só num ponto de vista didático, pois o vazio de uma praça ou de uma estrada, exterior em relação aos edifícios que 0 ladeiam, é interior em relação à cidade. [E mais:] Os métodos que caracterizam [o projeto de] uma praça ou uma rua não são diferentes daqueles que se usam para definir as salas, as galerias, os pórticos ou os pátios de um salão. (1979, pp. 72-73; grifos meus)

Zevi ratifica, portanto, o que escreveu Alberti quatro séculos antes dele. Não há distinção, no que diz respeito à concepção do espaço arquitetônico, entre a construção da casa e a edificação da cidade, ${ }^{12}$ razão pela qual, na arquitetura, podemos falar de espaços abertos e de espaços fechados, mas o espaço externo é alheio à arquitetura, quer teórica, quer metodologicamente falando.
Afinal, "Assim como as paredes, as colunas, etc. são elementos de que se compõem os edifícios, os edifícios são os elementos de que se compõem as cidades", escreveu Rossi (1995, p. 24), citando Durand. ${ }^{13}$ Desse modo, o espaço da rua, exterior em relação a um edifício em particular, conforma, ele próprio, em composição com cada uma das outras edificações da rua, um outro espaço interno, e assim sucessivamente.

Do ponto de vista metodológico, igualmente, tanto na construção do edifício quanto na construção da cidade estão presentes os atributos próprios e específicos do espacejar (Argan, 2000), a saber: a questão das proporções - o vocabulário tridimensional de que se vale o tektôn em seu ofício projetual -, da escala - inescapável na construção do espaço humano ${ }^{14}$-, da forma plástica - expressão material do ato de espacejar ${ }^{15}-$, dentre outros atributos projetuais próprios da arquitetura.

Destarte, ambas, a casa e a cidade, resultam da criação humana (arkhê); ambas são espaços construídos a partir de uma ação projetiva; ambas, ainda, compõem vazios, espaços internos que incluem o humano. A sequência de fotos a seguir ajuda a entender melhor essa ideia.

Por fim, a composição do vazio constitui a terceira especificidade do espaço da arquitetura. É essa a palavra-chave para a última, dados os limites deste texto, distinção epistemológica a ser assinalada no que diz respeito ao espaço da arquitetura.

Compor, convém lembrar, é criar um todo juntando, associando, diferentes partes precisamente esse o ofício do tektôn. Assim como o poeta compõe o poema ligando palavras distintas de uma língua, assim como 
Figuras 4, 5 e 6 - O espaço interno, ainda que externo à edificação, composto por larguras, alturas e profundidades
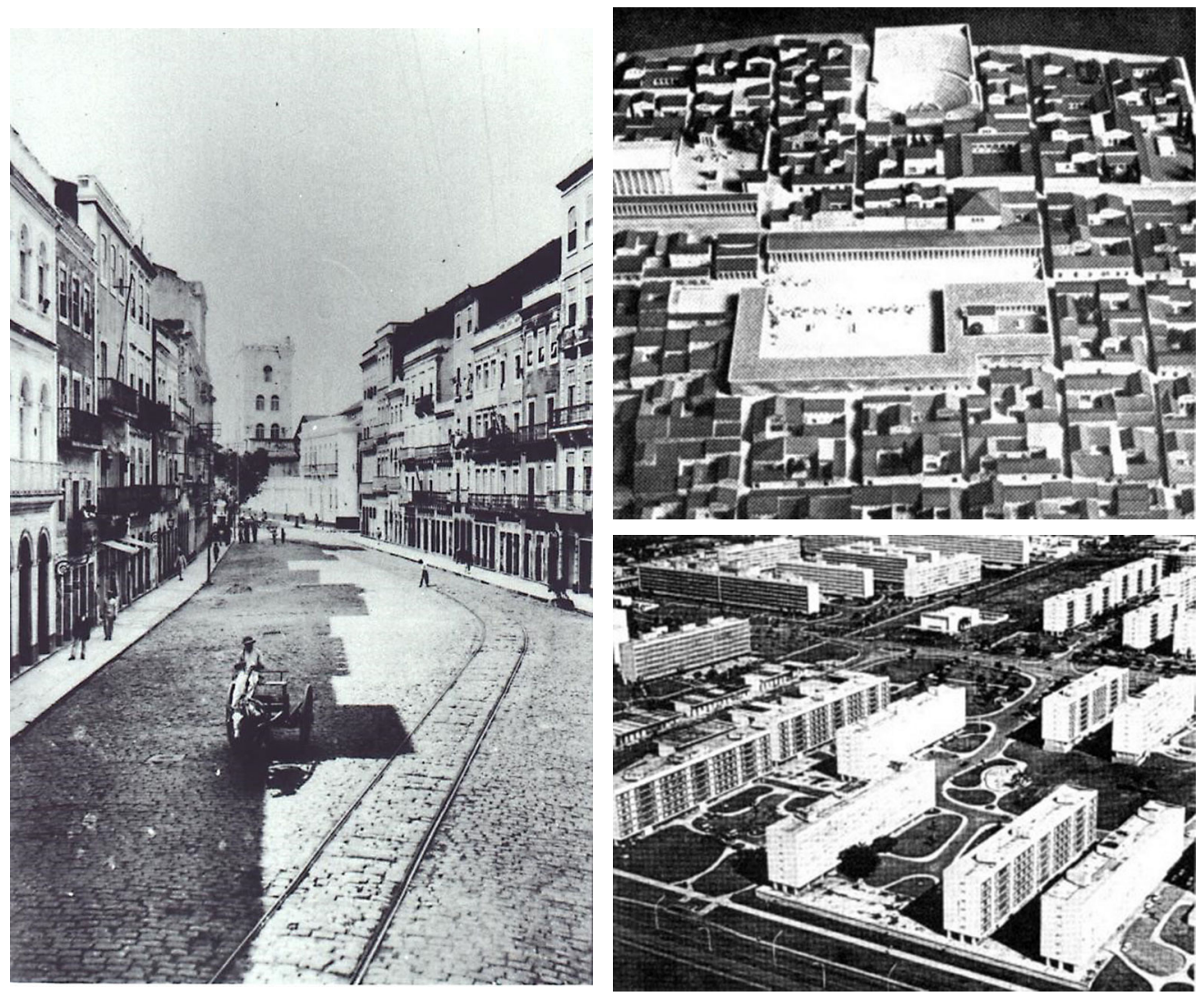

Fontes: Acervo da Fundação Joaquim Nabuco (Figura 4); Norberg-Schulz (1998, p. 200, Figura 5) e Murillo Marx (1980, p. 56, Figura 6).

o músico compõe sua melodia associando acordes diversos entre si, o tektôn lança mão de um vocabulário tridimensional, próprio do fazer arquitetônico, para compor o espaço da arquitetura.

Como composição, o principal ponto a destacar ante a especificidade do espaço da arquitetura é a ideia de limite, quer no lote, quer na gleba. 0 espaço arquitetônico resulta de uma ação projetiva que necessariamente limita e, nessa ação de limitar, constitui e define o espaço da arquitetura. Sem essa delimitação espacial, ter-se-ia ainda, tanto vertical quanto horizontalmente, o espaço natural, o espaço que se dá como espaço para o homem, vasto e indefinido. 
Figuras 7 e 8 - O espaço da arquitetura claramente delimitado em duas dimensões: projeto de casa, Mies van der Rohe (Figura 7), e no desenho esquemático de Borromini para a Igreja de Sant'Ivo (Figura 8)

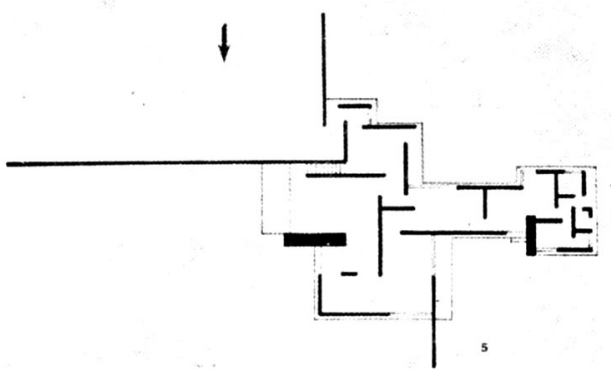

Fontes: Norberg-Schulz (1998, pp. 216 e 191), respectivamente

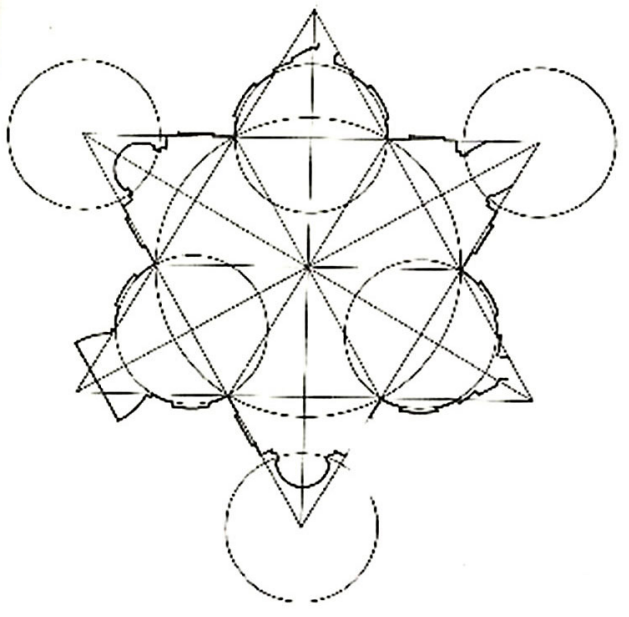

É essa ação de limitar, de demarcar o espaço preexistente para então criar o espaço da arquitetura, o ponto de partida - e de chegada - na composição do espaço arquitetônico. Nessa ação de limitar, explicitam-se alguns dos principais elementos compositivos do fazer arquitetônico, isto é, o vocabulário do qual lança mão o tektôn em seu ofício cotidiano.

Larguras, alturas e profundidades, por exemplo, são definidas nessa atividade projetiva de estabelecer limites. Com isso, são igualmente definidas a proporção, a simetria - que indica harmonia, equilíbrio entre os elementos compositivos da edificação, e não necessariamente repetição -, a escala, dentre outros elementos a partir dos quais se obtém a composição de um vazio onde os homens entram e vivem.
Essa ideia de composição espacial como consequência da habilidade do tektôn no manuseio do vocabulário tridimensional próprio do fazer arquitetônico, como especificidade, portanto, da criação do espaço da arquitetura, aparece, por exemplo, claramente, na proposição e na construção da Ringstrasse, a famosa rua em anel vienense do fim do século XIX. Comentando a construção dessa rua célebre da arquitetura europeia, Schorske anota precisamente esse ponto ao assinalar " [...] o poder linear da rua" [largura e profundidade], um espaço onde "a massa vertical [altura] está subordinada ao movimento plano, horizontal, da rua" (1988, p. 54; grifos meus).

A demarcação do limite físico - quer horizontal, quer vertical - é, pois, um ponto 
essencial para a composição do espaço interno que acolhe o humano, para a criação e para a especificidade do espaço da arquitetura. Elementos fundamentais do fazer arquitetônico, a exemplo da plástica - a forma regular, irregular, geométrica, orgânica, retilínea, curvilínea, etc. que esses limites assumem -, isto é, da expressão volumétrica do espaço da arquitetura, derivam precisamente desses limites compositivos (Tedeschi, 1976). De igual modo, a escala, cuja referência na arquitetura é o corpo humano e não o território -, deriva do estabelecimento desses limites projetuais, bem como da forma que eles adquirem.

Enfim, é justamente do conjunto desses atributos, da demarcação volumétrica, da explicitação do vocabulário do qual lança mão o tektôn no exercício compositivo que cotidianamente pratica, que provém o espaço interno, o vazio que acolhe o humano. A composição do espaço, isto é, de um vazio resultante de uma associação de elementos próprios e específicos da arte de edificar, constitui-se, pois, na terceira e última distinção epistemológica a anotar neste texto.

Diante do exposto, tem-se que o espaço da arquitetura, a exemplo do nó borromeu, constitui-se necessariamente a partir de uma inter-relação de três nós, ou três eixos, que atuam de modo associado. Em outras palavras, a definição do espaço da arquitetura exige, de modo simultâneo, a criação de um espaço interno destinado a acolher o humano, composto, necessariamente, a partir de um vocabulário projetual específico, indispensável à construção do teto e do muro.

Figuras 9 e 10 - O vazio, espaço interno, composto a partir das proporções, da escala e da sua expressão plástica - a forma

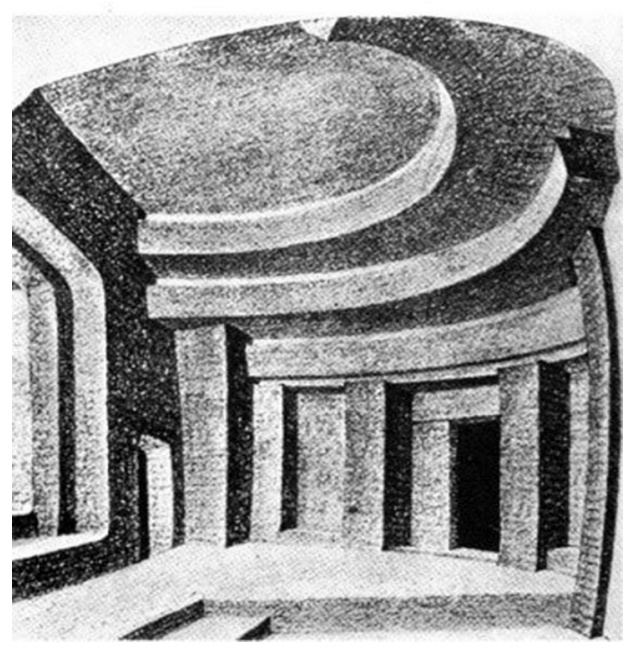

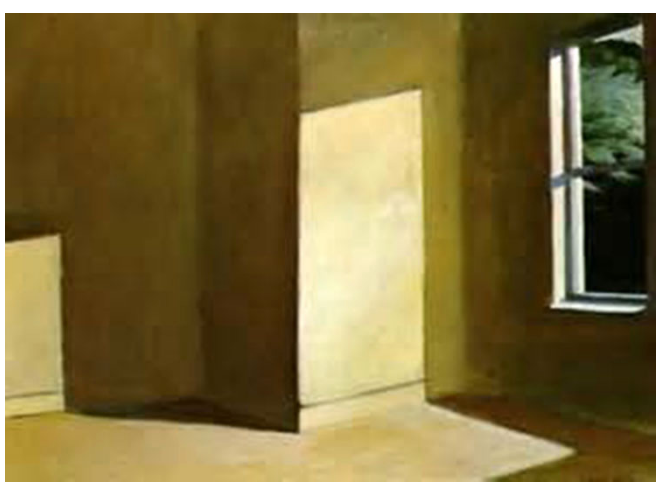


0 primeiro desses três eixos, mais perto da filosofia, diz respeito à edificação de um espaço cuja origem, concepção e apropriação se assentam na condição humana. Assim, o que a arquitetura principia, origina - arkhê -, com a composição do vazio é a própria construção do espaço humano. Em outras palavras, essa construção espacial é a um só tempo expressão e condição da aventura humana em sua experiência errante na face da Terra. Em outras palavras, ainda, esse espaço composto é a morada humana no sentido heideggeriano do termo, irredutível, portanto, à construção (tectônica) do edifício, conforme se anotou antes.

0 segundo eixo, de natureza teórico-metodológica, aponta para o fato de que, como morada humana, o espaço da arquitetura tem concepção, destinação e função específicas incluir, e nisso acolher, o humano. Para isso, tem especificidade teórica também específica - a construção do espaço interno -, cuja implicação mais evidente em termos epistemológicos é fazer do espaço externo algo alheio à arquitetura enquanto campo disciplinar.

0 terceiro eixo, mais próximo da arte, aponta para a composição do vazio como sendo, a um só tempo, objeto e objetivo da arte de edificar o ambiente construído. Assim, diferentemente de outros campos disciplinares, notadamente nas ciências sociais, o arquitetar não tem como objeto, tampouco como objetivo, quantificar, avaliar ou analisar o espaço edificado, ou seja, o espaço da arquitetura é necessariamente projetual.

É evidente que não se esgota aqui a questão da natureza do espaço da arquitetura. Não é esse o objetivo destas notas sumárias. 0 que se pretendeu foi chamar a atenção para os três eixos anotados - étimo-filosófico, teórico-metodológico e compositivo (tectônico) -, de modo a possibilitar àqueles menos familiarizados com a Teoria da Arquitetura uma aproximação conceitual das especificidades epistemológicas próprias do espaço que se constitui, e assim se define, como sendo a composição do vazio.

\section{Anotações finais}

É inquestionável que a interdisciplinaridade foi imprescindível para o processo de construção teórica da geografia, o que gerou, inclusive, duas grandes divisões (geografia física e geografia humana) e inúmeras subdivisões: geomorfologia, geopolítica, geoeconomia, biogeografia, geo-história, etc. De forma semelhante, a arquitetura e o urbanismo vêm buscando aportes complementares nas ciências sociais e humanas (geografia, sociologia, história, antropologia, psicanálise, dentre outras), de modo a ampliar possíveis interações conceituais entre elas. Com isso, possibilita a ampliação do debate conceitual no âmbito dessas ciências. No entanto, muito há ainda por se fazer nessas aproximações disciplinares.

A esse respeito, cabe registrar o que diz 0 geógrafo Marcelo Lopes de Souza: "0 aprendizado mútuo entre cientistas sociais e arquitetos precisa ser aprofundado" (2006, p. 58). E Souza vai mais além ao afirmar:

Os cientistas sociais envolvidos com pesquisa urbana precisam superar sua usual ignorância em matéria de arquitetura. A consciência da necessidade de maior intimidade com a dimensão estética e de funcionalidade dos objetos geográficos 
deve disseminar-se entre eles, que vão desde estilos arquitetônicos até a história do urbanismo, passando por análises morfológicas e visual. (Ibid.)

No campo da arquitetura, Lootsma (2000, p. 471) sublinha que "os arquitetos, com sua fixação em sua própria disciplina e suas soluções físicas, tendem a pôr o carro na frente dos bois [...]. [Desconhecem, assim, que] a arquitetura e o urbanismo já não são suficientes para entender, planejar e controlar a paisagem urbana".

Como se vê, muito há ainda por fazer com vista à construção de referências teóricas e de método que nos permitam, de um lado, explicitar as distinções epistemológicas quanto à noção de espaço na geografia e na arquitetura e, de outro, estabelecer as premissas conceituais que emergem do diálogo entre essas disciplinas.

\section{Lucia Leitão}

Universidade Federal de Pernambuco, Departamento de Arquitetura e Urbanismo, Programa de Pós-Graduação em Desenvolvimento Urbano leitaolu@gmail.com

\section{Norma Lacerda}

Universidade Federal de Pernambuco, Departamento de Arquitetura e Urbanismo, Programa de Pós-Graduação em Desenvolvimento Urbano norma_lac@yahoo.com.br

\section{Notas}

(1) Segundo Santos, "essa é a razão pela qual especialistas de outras disciplinas, não sabendo claramente o que fazem os geógrafos, renunciam a incluí-los nos seus próprios debates" (2006).

(2) O primeiro Tratado de Arquitetura, de Vítruvio, remonta aos anos 20 a. C. aproximadamente.

(3) Curiosamente, é nessa década que o espaço se torna o elemento protagonista da arquitetura a partir da contribuição notável de Bruno Zevi (1977).

(4) O espaço relativo é entendido por Harvey a partir de relações entre os objetos - o que implica custos, energia e tempo -, para vencer a fricção imposta pela distância.

(5) Para Soja, "o historiador, como crítico e observador social, e a história, como perspectiva interpretativa privilegiada, tornaram-se conhecidos nos círculos acadêmicos. Em contraste, a geografia e os geógrafos foram deixados com pouco mais do que descrição pormenorizada dos resultados, aquilo que passou a ser chamado pelos cronistas da disciplina de 'diferenciação de área dos fenômenos" (1993, p. 48). 
(6) O marxismo dos fins de século XIX caracterizava-se por sua forte vinculação ao historicismo e, desse modo, o espaço era aniquilado pelo tempo.

(7) Para Santos (2006, p. 67), “a palavra paisagem é frequentemente utilizada em vez da expressão configuração territorial. Esta é o conjunto de elementos naturais e artificiais que fisicamente caracterizam uma área. A rigor, a paisagem é apenas a porção da configuração territorial que é possível abarcar com a visão. Assim, quando se fala em paisagem, há, também, referência à configuração territorial e, em muitos idiomas, o uso das duas expressões é indiferente".

(8) Ver, a propósito, A composição do vazio (2001), documentário de Marcos Enrique Lopes sobre a vida e a obra de Evaldo Coutinho.

(9) "Si dans le mot architecture, commence avec le commencement ce qui détermine l'œuvre, nous devons comprendre arkhê à la fois comme príncipe originaire et comme ce qui tient en main le devenir de la réalisation du projet [...]". Tradução livre.

(10) Françoise Choay, a partir da leitura que faz do texto de Alberti, distingue, muito apropriadamente, o termo arquitetar do ato de edificar, atribuindo a este último um sentido antropológico. Neste texto, considerando os seus objetivos, os dois vocábulos são usados como sinônimos.

(11) "Houve quem dissesse que a água ou o fogo proporcionaram os princípios que fizeram com que se formassem as comunidades humanas. Nós, todavia, se considerarmos a utilidade e a necessidade de uma cobertura e de uma parede [um teto e muro] para reunir e manter em grupo os seres humanos, ficaremos convencidos de que foram certamente estes [o teto e o muro] os fatores mais importantes [para a formação das comunidades humanas]" (Alberti [1485], 2011, p. 138).

(12) Em pelo menos três momentos em De re aedificatoria, Alberti assinala que não há distinção teórico-metodológica na edificação do espaço humano. A saber, (i) “[...] a cidade é, na opinião dos filósofos, uma casa em ponto grande e, inversamente, a casa é uma cidade em ponto pequeno" (Livro I, cap. IX, p. 170); (ii) e, assim como na cidade há fórum e praças, assim nas casas haverá átrio, salão e outras divisões do mesmo gênero [...]" (Livro V, cap. II p. 321); e (iii): "Dissemos que a casa é uma pequena cidade. Por isso é necessário, na sua construção, ter em conta quase tudo aquilo que se aplica à construção da cidade" (Livro V, cap. XIV, p. 352), na edição consultada.

(13) DURAND, Jean-Nicolas-Louis (1802-5). Précis des leçons d'architecture données à l'École Polytechnique. Paris.

(14) “Enquanto o homem tiver duas mãos para usar e dois pés para caminhar, a escala humana é inescapável na arquitetura”, escreveu Krier (1975).

(15) A habilidade de espacejar é aqui entendida como sendo a habilidade humana para construir sua habitação. Uma habilidade presente em todas as culturas e em todos os tempos. 


\section{Referências}

ALBERTI, L. B. (2011). Da arte edificatória. Lisboa, Fundação Calouste Gulbenkian.

ANDRADE, M. C. de (2006). Geografia: ciência da sociedade. Recife, Editora UFPE.

ARGAN, G. (1966). El concepto del espacio arquitectónico: desde el barroco a nuestros días. Buenos Aires, Nueva Visión.

(2000). “A propósito do espaço interno". In: ARGAN, G. C. Projeto e destino. São Paulo, Ática.

BARBOSA, D. T. (2014). Novos Recifes, velhos negócios. Política da paisagem no processo contemporâneo de transformação da bacia do Pina - Recife/PE: uma análise do projeto Novo Recife. Dissertação de mestrado. Recife, Universidade Federal de Pernambuco.

CHOAY, F. (2006). Pour une anthropologie de l'espace. Paris, Éditions du Seuil.

CORRÊA, R. L. (2001). “Espaço: um conceito-chave da geografia”. In: CASTRO, I. E. de; GOMES, P. C. da C. e CORRÊA, R. L. (orgs.). Geografia: conceitos e temas. Rio de Janeiro, Bertrand Brasil.

CORRÊA, R. L. e ROSENDAHL, Z. (2000). “Apresentação: Geografia cultural: um século”. In: CORRÊA, R. L. e ROSENDAHL, Z. (orgs.). Geografia cultural: um século. Rio de Janeiro, Editora UERJ.

COUTINHO, E. (1977). O espaço da arquitetura. São Paulo, Perspectiva.

DUCAN, J. S. (2000). "Após-guerra civil: reconstruindo a geografia cultural como heterotipia". In: CORRÊA, R. L. e ROSENDAHL, Z. (orgs.). Geografia cultural: um século. Rio de Janeiro, Editora UERJ.

DUNLOP, J. (2010). Les 100 mots de géographie. Paris, Presses Universitaire de France.

FOUCAULT, M. (1976). La géographie doit bien être au coeur de ce dont je m'occupe. Hérodote, n. 1, (entrevista). Disponível em: https://travauxpublics.wordpress.com/1976/03/02/entretien-avecmichel-foucault/. Acesso em: 10 out 2015.

(1984). Dits et écrits 1984, Des espaces autres (conférence au Cercle d'études architecturales, 14 mars 1967). Architecture, Mouvement, Continuité, nº 5, pp. 46-49.

KRIER, R. (1975). Stuttgart: Teoria y practica de los espacios urbanos. Barcelona, Gustavo Gili.

LEFEBVRE, H. (1972). Espace et politique. Paris, Éditions Anthropos.

(1986). La production de l'espace. Paris. Éditions Anthropos.

LÉVI-STRAUSS, C. (2009). Natureza e cultura. Antropos - Revista de Antropologia, v. 3, ano 2, pp. 17-26.

LOOTSMA, B. (2000). "El nuevo paisage". In : KOOLHAAS, R. Mutaciones. Barcelona, Actar.

MARC, O. (1972). Psychanalise de la maison. Paris, Éditions de Seuil.

MARX, M. (1980). Cidade brasileira. São Paulo, Melhoramentos.

MUMFORD, L. (1982). A cidade na história: suas origens, desenvolvimento e perspectivas. São Paulo, Martins Fontes.

NORBERG-SCHULZ, C. (1998). Intenciones em arquitectura. Barcelona, Gustavo Gili. 
RAFFESTIN, C. (1993). “O que é território?”. In: RAFFESTIN, C. Por uma geografia do poder. São Paulo, Ática.

ROSSI, A. (1995). A arquitetura da cidade. São Paulo, Martins Fontes.

RYKWERT, J. (1997). On Adam's house in paradise-the idea of the primitive hut in architectural history. Cambridge, Massachusetts, MIT Press.

SALIGNON, B. (1997). "Fondements de la psychanalyse et architecture”. In: SALIGNON, B. La cité n'appartient à persone. Saint Maximin, Théétète éditions.

(2001a). "Architecture et logos". In : SALIGNON, B. Rythme et arts - Les fins de l'architecture. Lecques, Théétète Éditions.

(2001b). “Qu'est-ce que I'architecture?” In: SALIGNON, B. Rythme et arts-Les fins de I'architecture.Lecques, Théétète éditions.

SANTANA. J. (2008). Alguns pontos sobre a geografia. Elementos de debate. Recife, mimeo.

SANTOS, M. (2006). A natureza do espaço. Técnica, tempo, razão e emoção. São Paulo, Editora da Universidade de São Paulo.

SCHORSKE, C. (1988). Viena fin-de-siècle. São Paulo, Companhia das Letras.

SILVA, B. (coord.) (1986). Dicionário de ciências sociais. Rio de Janeiro, Editora da Fundação Getúlio Vargas.

SOJA, E. W. (1993). Geografia pós-modernas. A reafirmação do espaço na teoria social crítica. Rio de Janeiro, Jorge Zahar.

SOUZA. M. L. de (2006). Mudar a cidade: uma introdução crítica ao planejamento e à gestão urbana. Rio de Janeiro, Bertrand.

TEDESCHI, E. (1976). Teoría de la arquitectura. Buenos Aires, Ediciones Nueva Visión.

VITTE, A. C. (2007). O desenvolvimento do conceito de paisagem e a sua inserção na geografia física. Mercator (UFC), v. 6, pp. 71-78.

ZEVI, B. (1977). Saber ver a arquitectura. Lisboa, Arcádia.

(1979). Arquitectura in nuce-uma definição de arquitectura. Lisboa, Editorial Minerva.

Texto recebido em $14 /$ jan/2016

Texto aprovado em 31/mar/2016 